\title{
CCN1/Cyr61-PI3K/AKT signaling promotes retinal neovascularization in oxygen-induced retinopathy
}

\author{
YU DI $^{1}$, YIOU ZHANG ${ }^{2}$, QINGZHU NIE ${ }^{1}$ and XIAOLONG CHEN ${ }^{1}$ \\ ${ }^{1}$ Department of Ophthalmology, Shengjing Affiliated Hospital, China Medical University, Shenyang, Liaoning 110004; \\ ${ }^{2}$ Graduate School, China Medical University, Shenyang, Liaoning 110122, P.R. China
}

Received March 9, 2015; Accepted October 6, 2015

DOI: $10.3892 / \mathrm{ijmm} .2015 .2371$

\begin{abstract}
Retinal neovascularization (RNV) is a characteristic pathological finding of retinopathy of prematurity (ROP). Cysteine-rich 61 [Cyr61, also known as CCN family member 1 (CCN1)] has been reported to mediate angiogenesis. The aim of the present study was to investigate the mechanisms of CCN1/Cyr61-phosphoinositide 3-kinase (PI3K)/AKT signaling in ROP. The contribution of CCN1 to human umbilical vein endothelial cell (HUVEC) proliferation and apoptosis under hypoxic conditions was determined using a cell counting kit-8 (CCK-8) and Annexin V/propidium iodide (PI) staining, respectively, as well as using siRNA targeting CCN1 (CCN1 siRNA). The cells exposed to hypoxia were also treated with the PI3K/AKT inhibitor, LY294002. In addition, mouse pups with oxygen-induced retinopathy (OIR) were administered an intravitreal injection of CCN1 siRNA. RNV was assessed by magnesium-activated adenosine diphosphate-ase (ADPase) staining. RT-qPCR, western blot analysis, immunofluorescence staining and immunohistochemistry were used to detect the distribution and expression of CCN1, PI3K and AKT. Exposure to hypoxia increased the neovascularization clock hour scores (from $1.23 \pm 0.49$ to $5.60 \pm 0.73, \mathrm{P}<0.05$ ) and the number of preretinal neovascular cells, as well as the mRNA and protein expression levels of CCN1, PI3K and AKT (all P<0.05). The injection of CCN1 siRNA decreased the neovascularization clock hour scores and the number of preretinal neovascular cells $(1.53 \pm 0.72$ vs. $4.76 \pm 1.04 ; 12.0 \pm 2.8$ vs. $31.4 \pm 2.6$, respectively, both $\mathrm{P}<0.05$ ), as well as the mRNA and protein expression levels of CCN1, PI3K and AKT (protein, -45.3, -22.5 and $-28.4 \%$; mRNA, $-43.7,-58.7$ and $-42.9 \%$, respectively, all $\mathrm{P}<0.05)$ compared to the administration of scrambled
\end{abstract}

Correspondence to: Dr Xiaolong Chen, Department of Ophthalmology, Shengjing Affiliated Hospital, China Medical University, No. 36 Sanhao Street, Heping, Shenyang, Liaoning 110004, P.R. China E-mail: medscidy@126.com

Key words: cysteine-rich 61, retinal neovascularization, retinopathy of prematurity, human umbilical vein endothelial cells, phosphatidylinositol 3-kinase, protein kinase B/AKT
siRNA under hypoxic conditions. Treatment with LY294002 decreased the mRNA and protein expression levels of CCN1 in the cells exposed to hypoxia (both $\mathrm{P}<0.05$ ). The administration of CCN1 siRNA resulted in less severe neovascularization in the eyes of the the mouse pups with OIR. Thus, out data suggest that CCN1 plays an important role in RNV in ROP, and may thus be a potential target for the prevention and treatment of ROP.

\section{Introduction}

Retinal neovascularization (RNV) is a characteristic pathological finding of a number of retinal diseases, including retinopathy of prematurity (ROP), proliferative diabetic retinopathy (PDR) and retinal vein occlusion (RVO) $(1,2)$. ROP is a leading cause of vision impairment and blindness in childhood $(3,4)$. If left untreated, it can lead to retinal fibrovascularization, and can ultimately cause vitreous hemorrhage, tractional retinal detachment and vision loss (5). For many years, the treatment of RNV was limited to laser therapy (6) and cryotherapy (7) on the avascular zone, which, while effectively reducing severe vision loss, also led to serious side-effects (7). Thus, it is important to study RNV pathogenesis and to develop novel therapies. It is clear from previous research that some progress has been made in relation to the pharmacological inhibition of proangiogenic factors (8-11). However, further investigations are required to provide effective and non-invasive treatment strategies.

The matricellular protein, $\mathrm{CCN}$ family member 1 (CCN1), also known as the cysteine-rich protein 61 (Cyr61), is an extracellular matrix (ECM)-associated immediate early gene-encoded protein (12) whose expression is highly restricted and dynamic at sites of vascularization and skeletogenesis during development and pathological states (13). CCN1/Cyr61 was the first cloned member of the CCN family (14-16) and has been reported to mediate cell adhesion, stimulate chemotaxis, increase growth factor-induced DNA synthesis, improve cell survival and enhance angiogenesis (17). CCN1 can also modulate the activities of several ECM proteins, growth factors and cytokines, including transforming growth factor- $\beta$ (TGF- $\beta$ ), tumor necrosis factor- $\alpha$ (TNF- $\alpha$ ), vascular endothelial growth factor (VEGF), hypoxia-inducible factor-1 $\alpha$ (HIF-1 $\alpha)$ and bone morphogenetic proteins $(18,19)$.

The phosphoinositide 3-kinase (PI3K)/AKT signaling pathway is essential to angiogenesis (20). Recent research 
has demonstrated that $\mathrm{CCN} 1 / \mathrm{Cyr} 61$ induces the expression of monocyte chemoattractant protein-1 (MCP-1) through the activation of the focal adhesion kinase (FAK), PI3K/AKT and nuclear factor (NF) $\kappa \mathrm{B}$ signaling pathways in chorioretinal vascular endothelial cells (21). In addition, a previous study indicated that the PI3K/AKT pathway is required for the hypoxia-induced expression of HIF-1 $\alpha$ and VEGF in choroidal neovascularization (20). It has also been suggested that targeting the PI3K/AKT pathway may be a possible treatment strategy for RNV (22).

Therefore, in the present study, we hypothesized that the CCN1/Cyr61-PI3K/AKT signaling pathway may promote retinal angiogenesis in ROP. In order to confirm this hypothesis, we investigated the angiogenic effects of CCN1/Cyr61 in human umbilical vein endothelial cells (HUVECs). In addition, CCN1/Cyr61-PI3K/AKT signaling in the retina was evaluated using a mouse pup model of oxygen-induced retinopathy (OIR).

\section{Materials and methods}

siRNA vector construction. siRNA targeting CCN1 (CCN1 siRNA) and scrambled siRNA were purchased from GenePharma Co., Ltd. (Shanghai, China), and used according to previously published methods $(23,24)$. The sequences were as follows: CCN1 (Cyr61-homo-553) sense, 5'-GGG AAA GUU UCC AGC CCA ACU TT-3' and antisense, 5'-AGU UGG GCU GGA AAC UUU CCC TT-3'; CCN1 (Cyr61-homo-789) sense, 5'-GAG GUG GAG UUG ACG AGA AAC TT-3' and antisense, 5'-GUU UCU CGU CAA CUC CAC CUC TT-3'; CCN1 (Cyr61homo-1072) sense, 5'-GCA AGA AAU GCA GCA AGA CCA TT-3' and antisense, 5'-UGG UCU UGC UGC AUU UCU UGC TT-3'; CCN1 (Cyr61-homo-1268) sense, 5'-GAU GAU CCA GUC CUG CAA AUG TT-3' and antisense, 5'-CAU UUG CAG GAC UGG AUC AUC TT-3'; and scrambled siRNA sense, 5'-UUC UCC GAA CGU GUC ACG UTT-3' and antisense, 5'-ACG UGA CAC GUU CGG AGA ATT-3'. The siRNA were cloned into the pGPU6/GFP/Neo siRNA expression vector kit (GenePharma,Ltd.) tocreate the GPU6/GFP/Neo-Cyr61 siRNA and the pGPU6/GFP/Neo-scrambled siRNA plasmids. The plasmids contained the $B b s 1$ and $B a m \mathrm{H} 1$ restriction sites. All plasmids contained green fluorescent protein (GFP). The Cyr61-homo-1072 construct yielded the optimal results (data not shown), and was thus used in the following experiments.

Cell culture and exposure to hypoxia. HUVECs were purchased from Cell Systems (Kirkland, WA, USA) and cultured in Dulbecco's minimum essential medium (DMEM; HyClone, Logan, UT, USA) with $10 \%$ fetal bovine serum (FBS; HyClone, Thermo Fisher Scientific, Waltham, MA, USA) in a $37^{\circ} \mathrm{C}$ humidified atmosphere containing $95 \%$ air and $5 \% \mathrm{CO}_{2}$. Subconfluent monolayers of HUVECs from passages 3 to 10 were used in the following experiments.

The HUVECs were subsequently divided into the normoxia $\left(20 \% \quad \mathrm{O}_{2} / 5 \% \quad \mathrm{CO}_{2} / 75 \% \quad \mathrm{~N}_{2}\right)$ and hypoxia groups $\left(1 \% \mathrm{O}_{2} / 5 \% \mathrm{CO}_{2} / 94 \% \mathrm{~N}_{2}\right)$. The hypoxia group was further subdivided into the hypoxia group, the hypoxia-scrambled siRNA group (transiently transfected with scrambled siRNA) and the hypoxia-CCN1 siRNA group (transiently transfected with CCN1 siRNA). The plasmids (500 ng/ $\mu$ l) were transiently transfected into the HUVECs using Lipofectamine 2000 (Invitrogen, Carlsbad, CA, USA).

The PI3K/AKT inhibitor, LY294002, was used to treat the cells exposed to hypoxia to determine the effects of inhibiting this pathway. The cells were cultured under hypoxic conditions in the presence of LY294002 (Sigma, St. Louis, MI, USA) (40 $\mu \mathrm{mol} / 1$, dissolved in DMSO; the final concentration of DMSO in the cell culture was $0.1 \%$ ). The cells were treated with LY294002 for $30 \mathrm{~min}$ before being placed in the incubator. An apoptosis assay, western blot analysis and reverse-transcription quantitative PCR (RT-qPCR) were performed after $24 \mathrm{~h}$ of exposure to hypoxia.

Cell proliferation assay. The cell counting kit-8 (CCK-8) assay (C0038; Beyotime, Jiangsu, China) was used to evaluate cell proliferation. The HUVECs were plated in 96-well plates at a density of 2,000 cells/well. Cell proliferation was evaluated each day for 4 days following transfection. CCK-8 (10 $\mu \mathrm{l})$ was added to each well followed by incubation for $2 \mathrm{~h}$ at $37^{\circ} \mathrm{C}$. After 10 min of vortexing, the absorbance was measured in a microplate reader (Sunrise RC; Tecan, Mannedorf, Switzerland) at $450 \mathrm{~nm}$.

Apoptosis detection by flow cytometry. Apoptosis was measured using a fluorescein isothiocyanate (FITC) Annexin V Apoptosis Detection kit (BD Biosciences, San Diego, CA, USA) according to the manufacturer's instructions. The HUVECs were collected, washed in cold phosphate-buffered saline (PBS), and labeled with $5 \mu \mathrm{l}$ Annexin V-FITC and $5 \mu \mathrm{l}$ propidium iodide $(\mathrm{PI})$, and then incubated for $15 \mathrm{~min}$ at room temperature in the dark. Flow cytometry was immediately performed and the cells were analyzed using CellQuest software (BD Biosciences, Franklin Lakes, NJ, USA). Annexin V was set as the horizontal axis and PI was set as the vertical axis. Mechanically damaged cells were located in the upper left quadrant, late apoptotic or necrotic cells in the upper right quadrant, dual-negative and normal cells in the lower left quadrant, and early apoptotic cells in the lower right quadrant of the flow cytometry dot plot. The apoptotic rate was calculated as the ratio of early and late apoptotic cells to total cells, as previously described $(25,26)$.

Immunofluorescence staining. The HUVECs were washed twice with PBS and fixed with $4 \%$ paraformaldehyde for $30 \mathrm{~min}$. The cells were then washed with $0.1 \%$ Triton X-100 for $10 \mathrm{~min}$ and twice with PBS, and were incubated with $1 \%$ bovine serum albumin (BSA) at room temperature for $1 \mathrm{~h}$. The cells were incubated overnight with the following commercially available primary antibodies: rabbit anti-Cyr61 polyclonal antibody (ab24448; Abcam, Cambridge, UK), mouse anti-p-PI3K monoclonal antibody (sc-12929), or rabbit anti-p-AKT1/2/3 (Ser473) polyclonal antibody (sc-101629) (both from Santa Cruz Biotechnology Inc., Santa Cruz, CA, USA). The cells were washed thrice with PBS. The primary antibodies were replaced by isotype controls, which were used as negative controls. The cells were then treated with fluorescence-conjugated secondary antibody [FITCconjugated AffiniPure rabbit anti-goat IgG (H+L; ZF-0314), or tetramethylrhodamine (TRITC)]-conjugated AffiniPure goat anti-mouse IgG (H+L; ZF-0313) (Zhongshan Jinqiao 
Biotechnology Co., Ltd., Beijing, China) for $1 \mathrm{~h}$ and counterstained with $0.5 \mu \mathrm{g} / \mathrm{ml} \mathrm{4',6-diamidino-2-phenylindole} \mathrm{(DAPI;}$ Beyotime Institute of Biotechnology, Jiangsu, China) for 5 min. Images were digitally captured using a confocal laser scanning microscope (FV1000; Olympus Corp., Tokyo, Japan).

Animals. Specific pathogen-free healthy C57BL/6J newborn mice (female or male; $\mathrm{n}=240$; and their mothers) were obtained from the Animal Laboratory of China Medical University, Shenyang, China and were housed with their mothers. The room temperature was maintained at $23 \pm 2^{\circ} \mathrm{C}$. Light did not exceed 300 lux on a $12 \mathrm{~h}$ light-dark cycle.

All procedures and animal experiments were approved by the Animal Care and Use Committee of the China Medical University.

OIR. OIR was induced in the C57BL/6J mice as previously described in the study by Smith et al (27). Briefly, on postnatal day $(\mathrm{P}) 7$, the pups and their mothers were placed in homemade glass containers coupled to an RSS-5100 oxygen analyzer (Rex Xinjing Instrument Co., Ltd., Shanghai, China). The mice were exposed to hyperoxia $\left(75 \pm 2 \% \mathrm{O}_{2}\right)$ for 5 days (P7-P12), and were then re-exposed to normoxia (room air) for 5 days. The rationale of exposing mice to hyperoxia and then to normoxia was to emulate a state of relative hypoxia. Neovascularization occurred when the mice re-exposed to normoxia and peaked at P17, as previously observed (27). The mice were randomly divided into 4 groups: the normoxia, hyperoxia, hyperoxia-scrambled siRNA and hyperoxia-CCN1 siRNA groups ( $n=60 /$ group).

In the normoxia group, the newborn mice were maintained in room air from P0 to P17. In the hyperoxia group, OIR was induced by the mice being exposed to hyperoxia $\left(75 \pm 2 \% \mathrm{O}_{2}\right)$ for 5 days (P7-P12) and then re-exposed to normoxia (room air) for 5 days (P12-P17). The same OIR induction protocol was used in the hyperoxia-scrambled siRNA and hyperoxia-CCN1 siRNA groups. The mice were administered an intravitreal injection of $1 \mu \mathrm{l}(500 \mathrm{ng} / \mu \mathrm{l})$ of the scrambled siRNA plasmid or the CCN1 siRNA plasmid on P11 using a 33-gauge needle attached to a Hamilton syringe, and were returned to room air on P12, as previously described $(28,29)$. The mice in all 4 groups were anesthetized by an intraperitoneal injection of ketamine hydrochloride $(100 \mathrm{mg} / \mathrm{kg}$ body weight), and were then sacrificed by decapitation on P17 in order to collect the retinas for morphological and pathological examinations, as well as for mRNA and protein expression analyses. In the present study, the percentage of GFP-positive cells in the retina was used to assess the transfection rate 1 day after the intravitreal injection of siRNA. The transfection rate was approximately $80 \%$. In addition, after examination it was clear that transfection did not cause endophthalmitis or retinal detachment (data not shown), suggesting that the gene transfer was successful and did not affect the eyes.

Observation of $R N V$. Retinal vascular patterns were assessed on P17, as previously described (30). The eyes were enucleated and fixed with $4 \%$ paraformaldehyde for $3 \mathrm{~h}$. The retinas were then dissected, flat-mounted through 4 incisions in the center of the disc to divide them into 4 quadrants, as previously described (31) and processed for magnesium-activated adenosine diphosphate-ase (ADPase) staining. The ADPasestained retinas were then flat-mounted on microscope slides with a gelatin-coated cover slip and carefully examined using an Olympus B201 optical microscope (Olympus Corp.). For neovascularization grading evaluation under the microscope, each retina was divided into 12 -h clocks in order to assess the neovascularization clock hour scores, as previously described (32-34). Three independent reviewers blinded to grouping assessed the clock hour scores in order to assess the severity of neovascularization.

Quantification of preretinal neovascularization. To quantify preretinal neovascularization, the retinal structures were analyzed on 6- $\mu \mathrm{m}$ hematoxylin and eosin (H\&E)-stained sections, as previously described (35). Briefly, the eyes were enucleated, fixed and embedded in paraffin. Serial sections (6- $\mu \mathrm{m}$-thick) of whole eyes were cut sagittally, through the cornea and parallel to the optic nerve, and stained with H\&E. Vascular cell nuclei, identified under a light microscope (Olympus B201, Olympus Corp.), were considered to be associated with new vessels if they were found on the vitreal side of the internal limiting membrane (ILM), as previously described (35). Three independent reviewers blinded to grouping counted the cells.

Immunohistochemistry. Immunohistochemistry was performed using an SABC immunohistochemistry kit (Boster Bioengineering Co., Wuhan, China). Formalin-fixed, paraffinembedded eye tissue sections $(6-\mu \mathrm{m}$-thick) were placed on slides, deparaffinized in xylene and rehydrated by incubation in graded ethanol baths in PBS. Endogenous peroxidase was blocked with $3 \%$ hydrogen peroxide in methanol. The sections were then treated with $10 \%$ normal goat serum and incubated overnight with the following commercially available primary antibodies: rabbit anti-Cyr61 polyclonal antibody (ab24448; Abcam), mouse anti-p-PI3K monoclonal antibody (sc-12929), or rabbit anti-p-AKT1/2/3 (Ser473) polyclonal antibody (sc-101629) (both from Santa Cruz Biotechnology, Inc.) at $4^{\circ} \mathrm{C}$. The sections were incubated with biotinylated horse secondary antibody againts mouse IgG (ZB-2020; Zhongshan Jinqiao Biotechnology Co., Ltd.) and reacted with the avidin-biotinylated peroxidase complex. The primary antibody was replaced with PBS for the negative controls, and 3,3'-diaminobenzidine (DAB) was used as the chromogen. The sections were counterstained with hematoxylin, dehydrated and mounted. Images were digitally captured using an Olympus B201 optical microscope (Olympus).

Western blot analysis. The HUVECS and retinal tissue homogenates were lysed using $50 \mathrm{mM}$ Tris- $\mathrm{HCl}(\mathrm{pH} 8.0)$, $150 \mathrm{mM} \mathrm{NaCl}, 0.5 \%$ Nonidet $\mathrm{P}-40,0.5 \%$ sodium deoxycholate and phenylmethylsulfonyl fluoride (PMSF) (all from Sigma). Cell debris were removed by centrifugation at $12,000 \mathrm{rpm}$, $4^{\circ} \mathrm{C}$, for $20 \mathrm{~min}$. Protein levels were determined by bicinchoninic acid (BCA) assay (Beyotime Institute of Biotechnology).

For western blot analysis, protein samples $(30 \mu \mathrm{g})$ were run on $10 \%$ sodium dodecyl sulfate (SDS)-polyacrylamide gels and transferred onto polyvinylidene fluoride (PVDF) membranes (Millipore, Billerica, MA, USA). Non-specific sites on each blot were blocked with 5\% BSA diluted in TBS 
Table I. Primer sequences for used for RT-qPCR.

\begin{tabular}{|c|c|c|c|}
\hline Gene & Primer sequences $\left(5^{\prime} \rightarrow 3^{\prime}\right)$ & Product length (bp) & Temperature $\left({ }^{\circ} \mathrm{C}\right)$ \\
\hline \multicolumn{4}{|c|}{ Against HUVECs } \\
\hline GAPDH & $\begin{array}{l}\text { F: GCA CCG TCA AGG CTG AGA AC } \\
\text { R: TGG TGA AGA CGC CAG TGG A }\end{array}$ & 138 & 60 \\
\hline $\mathrm{AKT}$ & $\begin{array}{l}\text { F: TTG CTT TCA GGG CTG CTC A } \\
\text { R: } \quad \text { TCT TGG TCA GGT GGT GTG ATG }\end{array}$ & 230 & 60 \\
\hline PI3K & $\begin{array}{l}\text { F: CGG TGA CTG TGT GGG ACT TA } \\
\text { R: }\end{array}$ & 116 & 60 \\
\hline Cyr61 & $\begin{array}{l}\text { F: CGA GGT GGA GTT GAC GAG AA } \\
\text { R: GCA CTC AGG GTT GTC ATT GGT }\end{array}$ & 211 & 60 \\
\hline \multicolumn{4}{|c|}{ Against mouse retina } \\
\hline GAPDH & $\begin{array}{ll}\text { F: } & \text { CCC ATC TAT GAG GGT TAC GC } \\
\text { R: } & \text { TTT AAT GTC ACG CAC GAT TTC }\end{array}$ & 150 & 55 \\
\hline $\mathrm{AKT}$ & $\begin{array}{l}\text { F: AGC AAA CAG GCT CAC AGG TT } \\
\text { R: TAA GTC CTC CCC ATG TCC CT }\end{array}$ & 245 & 55 \\
\hline PI3K & $\begin{array}{l}\text { F: GGC TTG GAC CGA ATG CT } \\
\text { R: } \text { TTG TTG AAG GCT GTG GC }\end{array}$ & 143 & 55 \\
\hline Cyr61 & $\begin{array}{l}\text { F: AGA CCC TGT GAA TAT AAC TCC A } \\
\text { R: AAT TGC GAT TAA CTC ATT GTT T }\end{array}$ & 300 & 55 \\
\hline
\end{tabular}

F, forward; R, reverse; HUVECs, human umbilical vein endothelial cells; GAPDH, glyceraldehyde 3-phosphate dehydrogenase; PI3K, phosphoinositide 3-kinase; Cyr61, Cysteine-rich 61.

with $0.05 \%$ Tween-20 (TBST) for $2 \mathrm{~h}$. The membranes were incubated with specific primary antibodies overnight at $4^{\circ} \mathrm{C}$ [rabbit anti-Cyr61 polyclonal antibody (ab24448; Abcam), or mouse anti-p-PI3K monoclonal antibody (sc-12929) or rabbit anti-p-AKT1/2/3 (Ser473) polyclonal antibody (sc-101629) (Santa Cruz Biotechnology, Inc.)], followed by incubation with horseradish peroxidase-conjugated secondary antibody (ZB-5305; Zhongshan Jinqiao Biotechnology Co., Ltd.) for $60 \mathrm{~min}$. Intensive washing was performed between incubations. Signals were detected by enhanced chemiluminescence (Pierce Biotechnology, Rockford, IL, USA). Protein levels were determined by densitometric scanning of the protein bands using a GIS-2020 image-processing system (TechNew Group Co., Ltd., Shanghai, China) and normalized to the intensity of the glyceraldehyde 3-phosphate dehydrogenase (GAPDH) band (using a rabbit anti-mouse GAPDH polyclonal antibody, bsm-0978M; Biosynthesis Biotechnology Co., Ltd., Beijing, China).

$R T-q P C R$. Total RNA was extracted from the HUVECs and retinas using TRIzol reagent (Invitrogen). The RNA purity was determined using absorbance at 260 and $280 \mathrm{~nm}$ (A260/280). cDNA synthesis was performed using a reverse transcriptase kit (PrimeScript ${ }^{\mathrm{TM}}$ RT Reagent kit-Perfect Real-Time; Takara Bio, Otsu, Japan), according to the manufacturer's instructions. The primer sequences used in the HUVECs and retinas are presented in Table I. Quantitative (real-time) PCR was performed using the SYBR-Green PCR Master Mix (Premix Ex Taq ${ }^{\mathrm{TM}}$-Perfect Real-Time; Takara Bio) in a total volume of $20 \mu \mathrm{l}$ on a 7300 Real-Time PCR System (Applied
Biosystems, Foster City, CA, USA). All reactions involved an initial denaturation at $95^{\circ} \mathrm{C}$ for $30 \mathrm{sec}$ followed by 50 cycles of $95^{\circ} \mathrm{C}$ for $5 \mathrm{sec}$ and $60^{\circ} \mathrm{C}$ for $31 \mathrm{sec}$. GAPDH was used as the reference gene. The $\mathrm{Ct}$ value was defined as the number of PCR cycles in which the fluorescence signal exceeded the detection threshold value. First, the $\Delta \mathrm{Ct}$ value was calculated as follows: Ct gene - Ct GAPDH. Subsequently, the $\Delta \Delta \mathrm{Ct}$ value was calculated as follows: $\Delta \mathrm{Ct}$ treated - $\Delta \mathrm{Ct}$ control. Lastly, the $2^{-\Delta \Delta \mathrm{Ct}}$ value was calculated to represent the relative mRNA expression of target genes, as previously described (36).

Statistical analysis. SPSS 15.0 for Windows (SPSS Inc., Chicago, IL, USA) was used for statistical analysis. Data are expressed as the means \pm standard deviation (SD) of 3 independent experiments. Statistical significance was evaluated by one-way analysis of variance (ANOVA) with Fisher's least significant difference (LSD) test for post hoc analysis. A P-value $<0.05$ was considered to indicate a statistically significant difference.

\section{Results}

Silencing of CCN1 by CCN1 siRNA inhibits HUVEC proliferation and induces HUVEC apoptosis under hypoxic conditions. The first step of angiogenesis is endothelial cell proliferation. The cell growth curves of 24, 48, 72 and $96 \mathrm{~h}$, as assessed by the CCK-8 method, indicated that the growth rate was slower in the hypoxia-CCN1 siRNA group than in the hypoxia and hypoxiascrambled siRNA groups Fig. 1A). An FITC Annexin V apoptosis detection kit was used to evaluate the effects of 

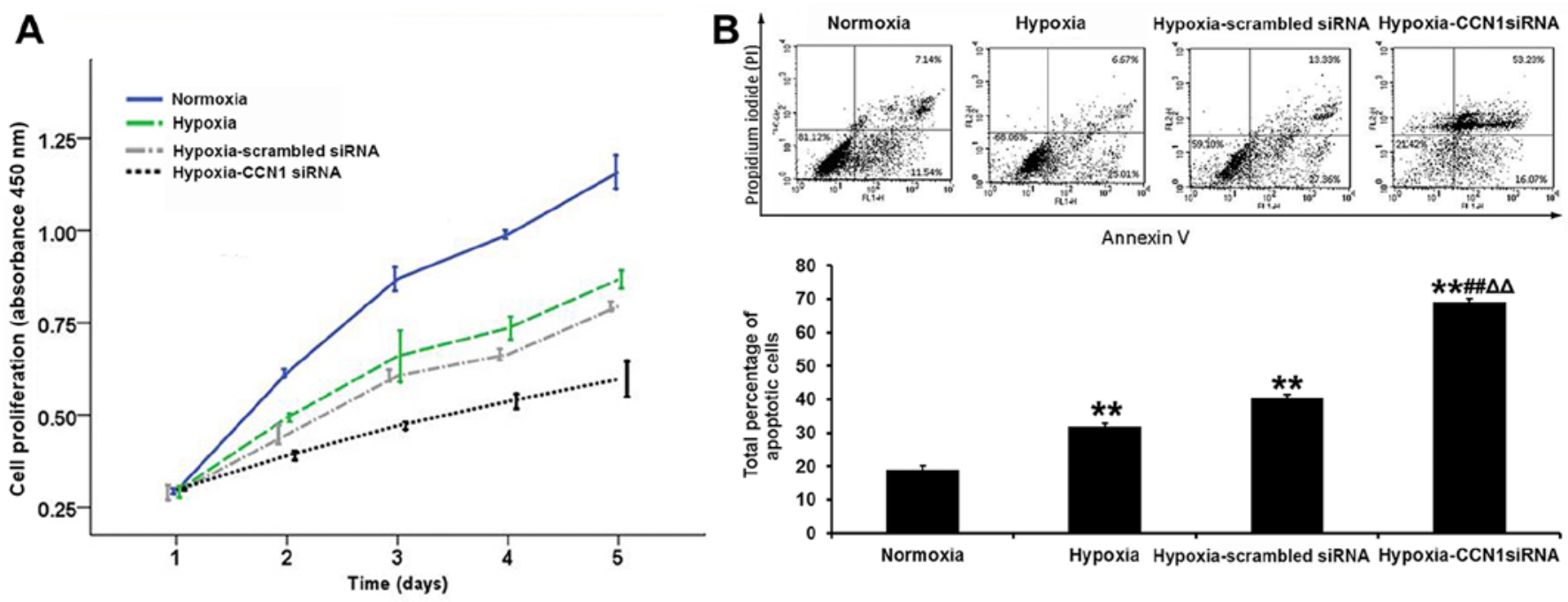

Figure 1. CCN family member 1 (CCN1) siRNA inhibits human umbilical vein endothelial cell (HUVEC) proliferation and induces HUVEC apoptosis under hypoxic conditions. HUVECs were divided into the normoxia group and the hypoxia group (HUVECs exposed to hypoxia); the hypoxia group was further subdivided into the hypoxia-scrambled siRNA group (HUVECs transfected with scrambled siRNA plasmid under hypoxic conditions) and the hypoxia-CCN1 siRNA group (HUVECs transfected with the CCN1 siRNA plasmid under hypoxic conditions). (A) Cell proliferation was evaluated by CCK-8 assay, each day for 4 days following transfection. Day 1 was the day of transfection. (B) Cell apoptosis was determined by flow cytometry using Annexin V/propidium iodide (PI) staining 2 days following transfection. Annexin V was set as the horizontal axis and PI was set as the vertical axis. Upper right (UR) quadrant, late apoptotic or necrotic cells; lower left (LL) quadrant, dual-negative/normal cells; lower right (LR) quadrant, early apoptotic cells; and upper left (UL) quadrant, mechanically damaged cells. The optical densities (at $450 \mathrm{~nm}$ ) and the total percentages of apoptotic cells are presented as the means \pm standard deviation (SD) of 3 independent experiments. ${ }^{* *} \mathrm{P}<0.01$ vs. the normoxia group; ${ }^{\# \#} \mathrm{P}<0.01$ vs. the hypoxia group; ${ }^{\triangle} \mathrm{P}<0.01$ vs. the hypoxia-scrambled siRNA group.

CCN1 siRNA on early and late apoptosis in the HUVECs. As shown in Fig. 1B, the early apoptotic rate was decreased, but the late apoptotic rate was significantly increased in the hypoxiaCCN1 siRNA group compared with the hypoxia-scrambled siRNA group (total apoptotic rate, $69.1 \pm 1.1$ vs. $40.4 \pm 1.0 \%$, $\mathrm{P}<0.01$; Fig. 1B). These results indicated that transfection of the cells with CCN1 siRNA exerted more prominent anti-proliferative and pro-apoptotic effects on the HUVECs.

Silencing of CCN1 by CCN1 siRNA inhibits HUVEC proliferation under hypoxic conditions by inhibiting PI3K/AKT signaling. Transfection with CCN1 siRNA decreased the mRNA expression levels of all 3 factors (CCN1, PI3K and AKT). Compared with the hypoxia-scrambled siRNA group, the mRNA levels of CCN1, PI3K and AKT in the hypoxiaCCN1 siRNA group were decreased by $78.2,50.0$ and $62.7 \%$, respectively (Fig. 2A). Immunofluorescence staining (Fig. 2B) and western blot analysis (Fig. 2C) revealed that the protein levels of CCN1, p-PI3K and p-AKT were higher in the hypoxia (protein, $0.53 \pm 0.02,0.36 \pm 0.01$ and $0.37 \pm 0.01$, respectively) and hypoxia-scrambled siRNA (protein, $0.49 \pm 0.07,0.42 \pm 0.03$ and $0.42 \pm 0.03$, respectively) groups compared with the normoxia group (protein, $0.22 \pm 0.03,0.23 \pm 0.02$ and $0.12 \pm 0.01$, respectively; all $\mathrm{P}<0.05$ ); however, no significant differences were observed between the hypoxia and hypoxia-scrambled siRNA groups (all P>0.05). In addition, the CCN1, p-PI3K and p-AKT protein expression levels were decreased in the hypoxia-CCN1 siRNA group compared with the hypoxia and hypoxia-scrambled siRNA groups (all $\mathrm{P}<0.05)$. Compared with the hypoxia-scrambled siRNA group, the CCN1, p-PI3K and p-AKT protein levels were decreased by 42.9, 26.2 and $50.0 \%$, respectively (all $\mathrm{P}<0.05$; Fig. $2 \mathrm{C}$ ).
PI3K/AKT inhibition decreases CCN1 expression. We performed an experiment using LY294002, an inhibitor of the PI3K/AKT pathway. The results revealed that the early apoptotic rate was decreased, but that the late apoptotic rate was significantly increased in the hypoxia-LY294002 group (total apoptotic rate, $58.1 \pm 1.2$ vs. $37.9 \pm 1.5 \%, \mathrm{P}<0.05$ ) (Fig. $3 \mathrm{~A}$ ). Compared with the hypoxia group, the mRNA expression of CCN1 in the hypoxia-LY294002 group was downregulated by 84.1\% ( $\mathrm{P}<0.05$; Fig. 3B). Compared with the hypoxia group, treatment with LY294002 decreased CCN1 protein expression in the cells exposed to hypoxia $(\mathrm{P}<0.05$; Fig. $3 \mathrm{C})$. These results suggest that a PI3K/AKT inhibitor may be used to decrease $\mathrm{CCN} 1$ expression, and that this process involves an autocrine loop.

Silencing of CCN1 by CCN1 siRNA inhibits RNV in a mouse pup model of OIR. To determine whether the silencing of CCN1 using CCN1 siRNA suppresses oxygen-induced ischemic RNV, we examined the retinal vasculature using an ADPase assay in retinal flat-mounts on P17. In our model of OIR, in the mice treated with CCN1 siRNA, alterations in vessel morphology and distribution were observed (in the flat mount image; Fig. 4A). Compared with the hyperoxia group $(5.60 \pm 0.73)$, the retinas from the hyperoxia-CCN1 siRNA group had less severe neovascular tufts and regions of nonperfusion, vascular tortuosity and less irregular expansion $(1.53 \pm 0.72, \mathrm{P}<0.05)$; these values were still slightly higher than in the normoxia group $(1.23 \pm 0.49, \mathrm{P}<0.05)$, but much lower than in the hyperoxia-scrambled siRNA group $(4.76 \pm 1.04$, $\mathrm{P}<0.05$ ) (Fig. 4A).

To further confirm the effects of CCN1 siRNA on RNV, we quantified the number of preretinal neovascular cells, a 

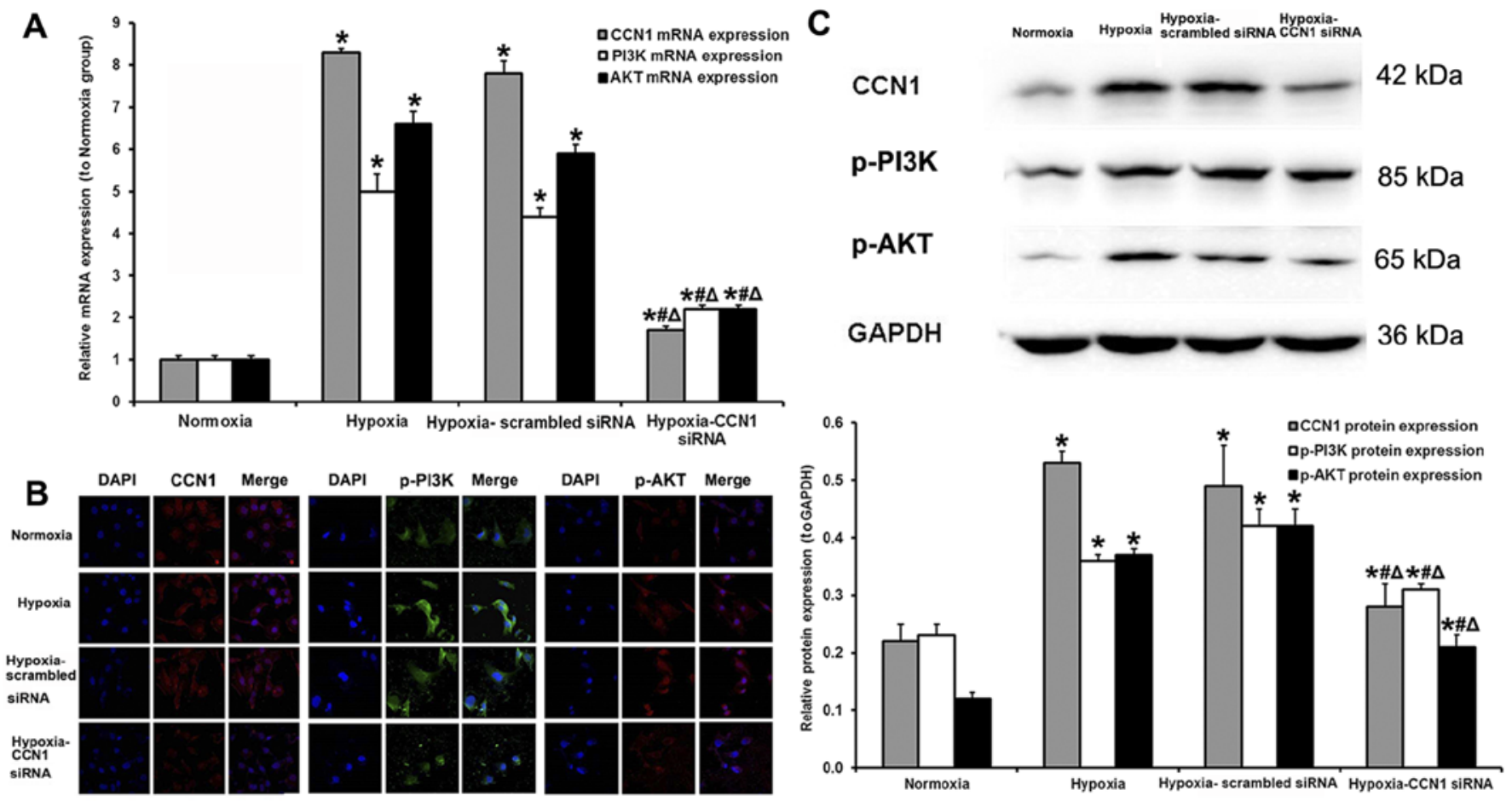

Figure 2. CCN family member 1 (CCN1) siRNA inhibits human umbilical vein endothelial cell (HUVEC) proliferation under hypoxic conditions through the inhibition of the phosphoinositide 3-kinase (PI3K)/AKT signaling pathway. (A) CCN1, PI3K and AKT mRNA expression levels were meausred by RT-qPCR 2 days following transfection. GAPDH was used as the internal control. (B) CCN1, p-PI3K and p-AKT protein expression levels were deteremined by immunofluorescence staining 2 days following transfecton. Red, TRITC; green, FITC; blue, DAPI (magnification, x600). (C) CCN1, p-PI3K and p-AKT protein expression levels were measured by western blot analysis 2 days following transfection. Protein expression was normalized to GAPDH. Data are presented as the means $\pm \mathrm{SD}$ of 3 independent experiments. ${ }^{*} \mathrm{P}<0.05$ vs. the normoxia group; ${ }^{~} \mathrm{P}<0.05$ vs. the hypoxia group; ${ }^{\wedge} \mathrm{P}<0.05$ vs. the hypoxia-scrambled siRNA group.

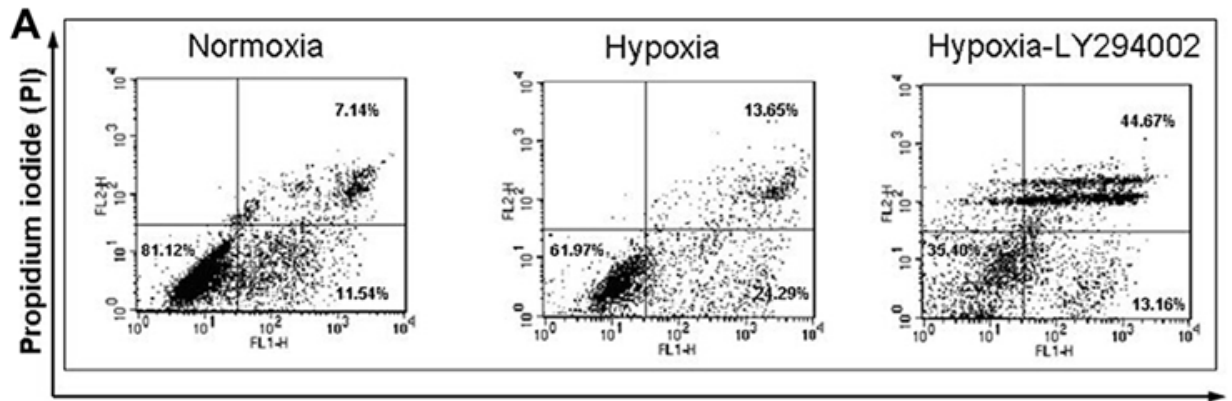

Annexin V
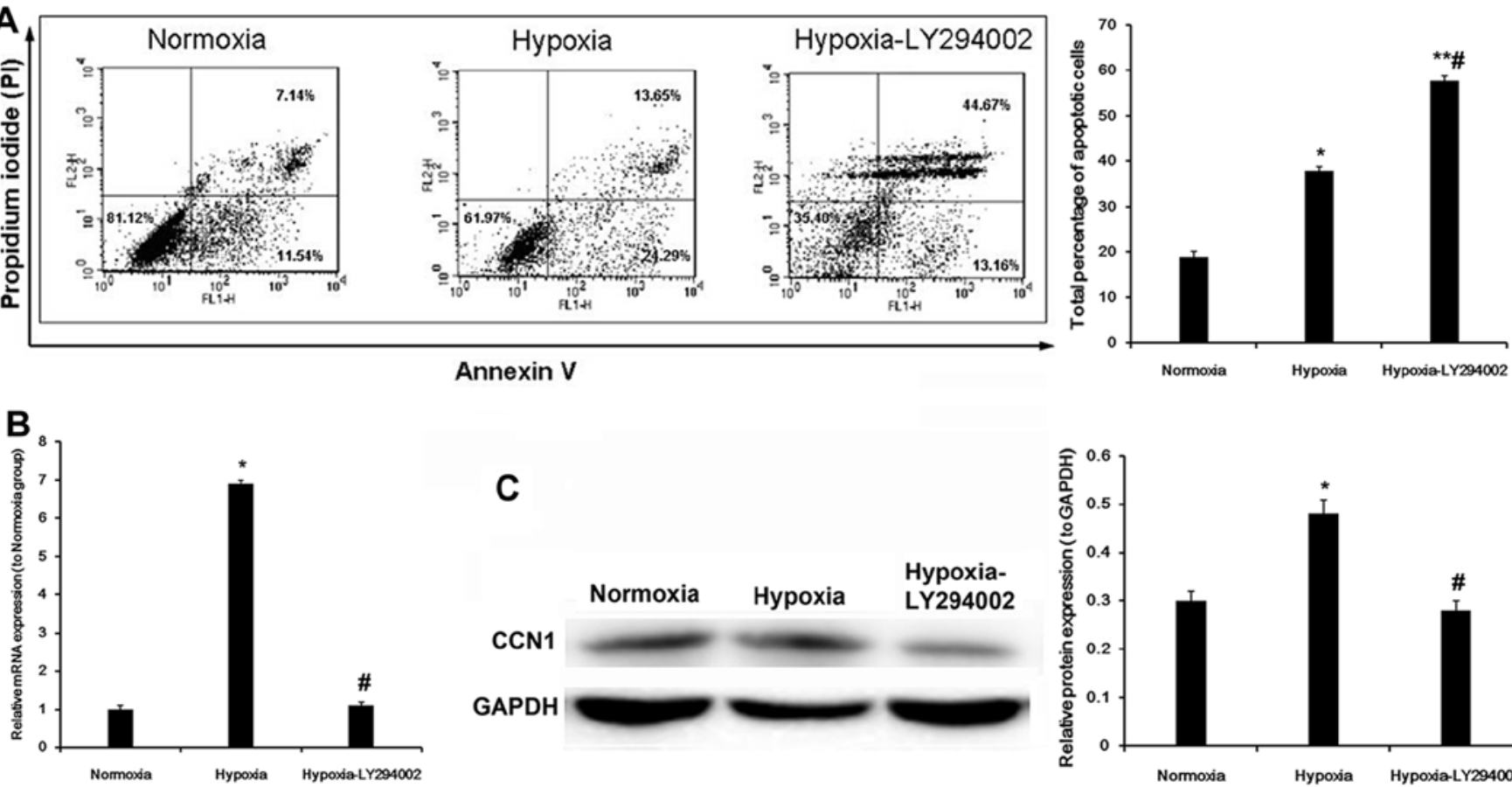

C

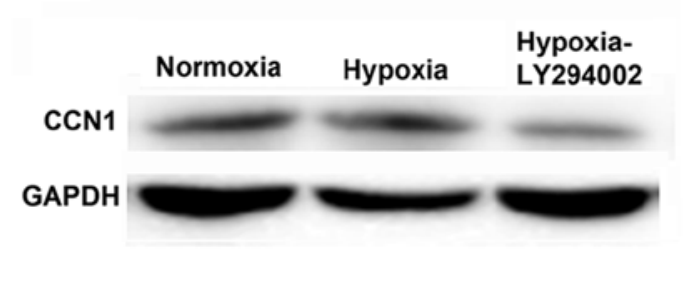

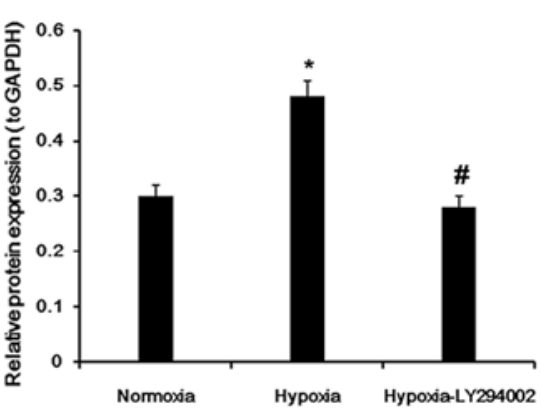

Figure 3. Effects of phosphoinositide 3-kinase (PI3K)/AKT inhibitor on human umbilical vein endothelial cell (HUVEC) apoptosis and CCN family member 1 (CNN1) expression under hypoxic conditions. HUVECs were treated with $40 \mu \mathrm{mol} / 1$ of LY294002, a PI3K/AKT inhibitor, for 30 min, and then cultured under hypoxic conditions $\left(1 \% \mathrm{O}_{2} / 5 \% \mathrm{CO}_{2} / 94 \% \mathrm{~N}_{2}\right.$ ) for $24 \mathrm{~h}$. (A) Cell apoptosis was determined by flow cytometry using Annexin V/propidium iodide (PI) staining. Upper right (UR) quadrant, late apoptotic or necrotic cells; lower left (LL) quadrant, dual-negative/normal cells; lower right (LR) quadrant, early apoptotic cells; and upper left (UL) quadrant, mechanically damaged cells. (B) CNN1 mRNA expression levels were measured by RT-qPCR. GAPDH was used as an internal reference. (C) CNN1 protein expression levels were measured by western blot analysis. Protein expression was normalized to GAPDH. Data are presented as the means \pm SD of 3 independent experiments. ${ }^{*} \mathrm{P}<0.05$ and ${ }^{* *} \mathrm{P}<0.01$ vs. the normoxia group; ${ }^{*} \mathrm{P}<0.05$ vs. the hypoxia group. 


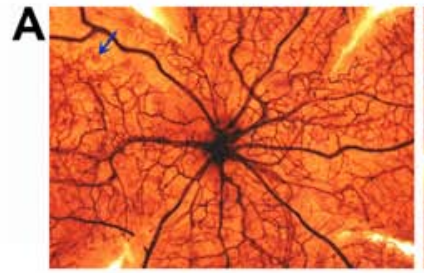

Normoxia

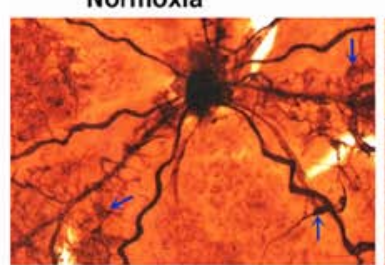

Hyperoxia -scrambled siRNA

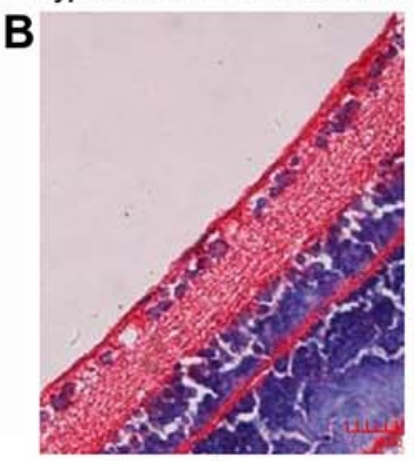

Normoxia

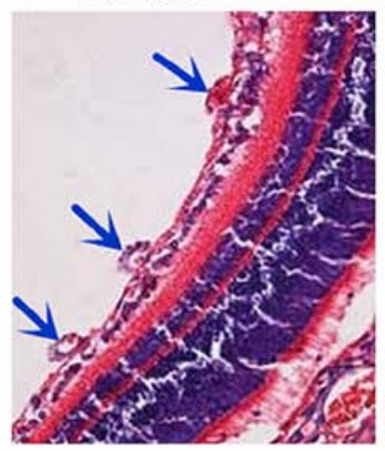

Hyperoxia -scrambled siRNA

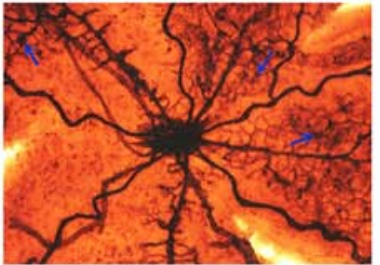

Hyperoxia

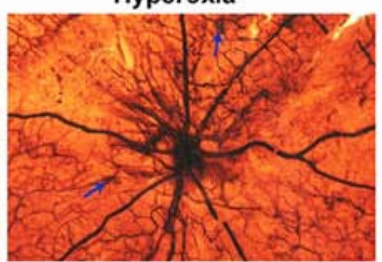

Hyperoxia-CCN1 siRNA

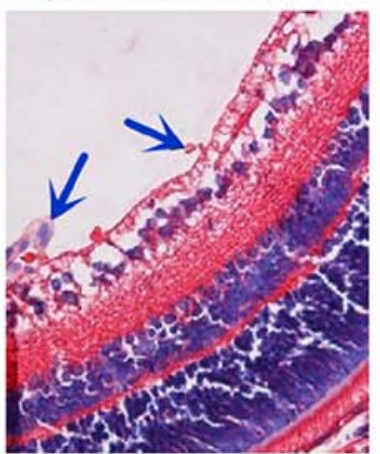

Hyperoxia

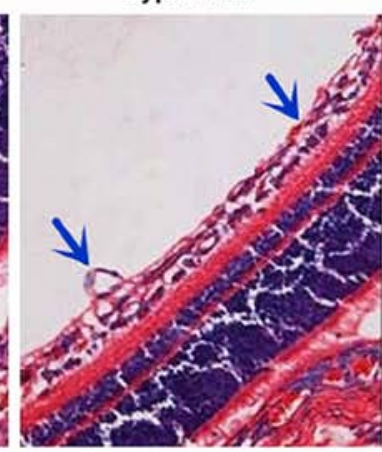

Hyperoxia-CCN1 siRNA
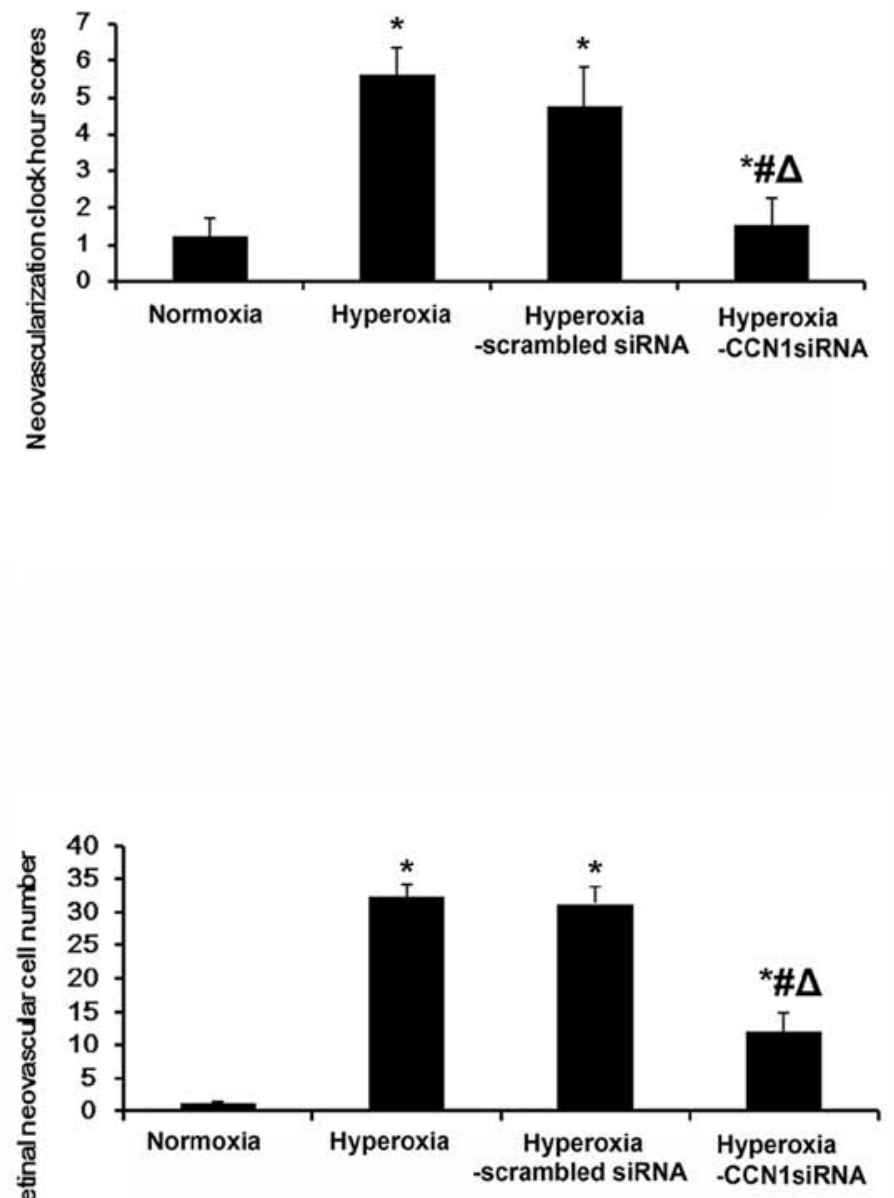

Figure 4. CCN family member 1 (CCN1) siRNA inhibits retinal neovascularization in a mouse pup model of oxygen-induced retinopathy (OIR). In the normoxia group, newborn mice were maintained in room air from postnatal day (P)0 to P17. In the hyperoxia group, newborn mice were exposed to hyperoxia for 5 days (P7-P12) and were then re-exposed to normoxia (room air) for 5 days. The OIR induction protocol was used in the hyperoxia-scrambled siRNA and hyperoxiaCCN1 siRNA groups. The mice received an intravitreal injection of $1 \mu 1(500 \mathrm{ng} / \mu \mathrm{l})$ of scrambled siRNA plasmids or CCN1 siRNA plasmids on P11, and were then re-exposed to room air on P12. Mice were sacrificed on P17 to collect the retinas. (A) ADPase staining of retinal flat-mounts (magnification, x100). The blue arrows indicate neovascularization. Three independent reviewers blinded to grouping assessed the clock hour scores in order to assess the severity of neovascularization. Data are presented as the means \pm SD ( $\mathrm{n}=10$ experiments). (B) Preretinal neovascular cells were counted on 10 non-continuous sections per eye, 10 eyes/group, and averaged. The blue arrows indicate vascular endothelial cells breaking through the inner limiting membrane (magnification, $\mathrm{x} 400$ ). Three reviewers blinded to grouping counted the cells. Data are presented as the means \pm SD from 10 non-continuous sections per eye, 10 eyes per group ( $\mathrm{n}=100$ sections). ${ }^{*} \mathrm{P}<0.05$ vs. the normoxia group; ${ }^{\sharp} \mathrm{P}<0.05$ vs. the hyperoxia group; ${ }^{\circ} \mathrm{P}<0.05$ vs. the hyperoxia-scrambled siRNA group.

characteristic of OIR (37). Preretinal neovascular cells growing in the vitreous humor were counted on 10 non-continuous cross-sections from each eye, according to a previously established method (35). As shown in Fig. 4B, the numbers of preretinal neovascular cells in the retinas from the hyperoxia group $(32.5 \pm 1.8)$ and the hyperoxia-scrambled siRNA group $(31.4 \pm 2.6)$ were significantly higher than those in the retinas from the normoxia group (1.3 \pm 0.2$)$ (both $\mathrm{P}<0.05$; Fig. 4B). Moreover, the numbers of preretinal neovascular cells in the hyperoxia-CCN1 siRNA group (12.0 \pm 2.8$)$ were significantly lower than those in the retinas from the hyperoxia and hyperoxia-scrambled siRNA groups (both $\mathrm{P}<0.05$ ), confirming the anti-neovascularization effects of the silencing of CCN1 (by CCN1 siRNA) on the retina.

Silencing of CCN1 by CCN1 siRNA inhibits RNV by inhibiting PI3K/AKT signaling in a mouse pup model of OIR. RT-qPCR was used to measure the CCN1, PI3K and AKT mRNA expression levels in the retinal samples. In the hyperoxia and hyperoxia-scrambled siRNA groups, the CCN1 (+244 and 
A
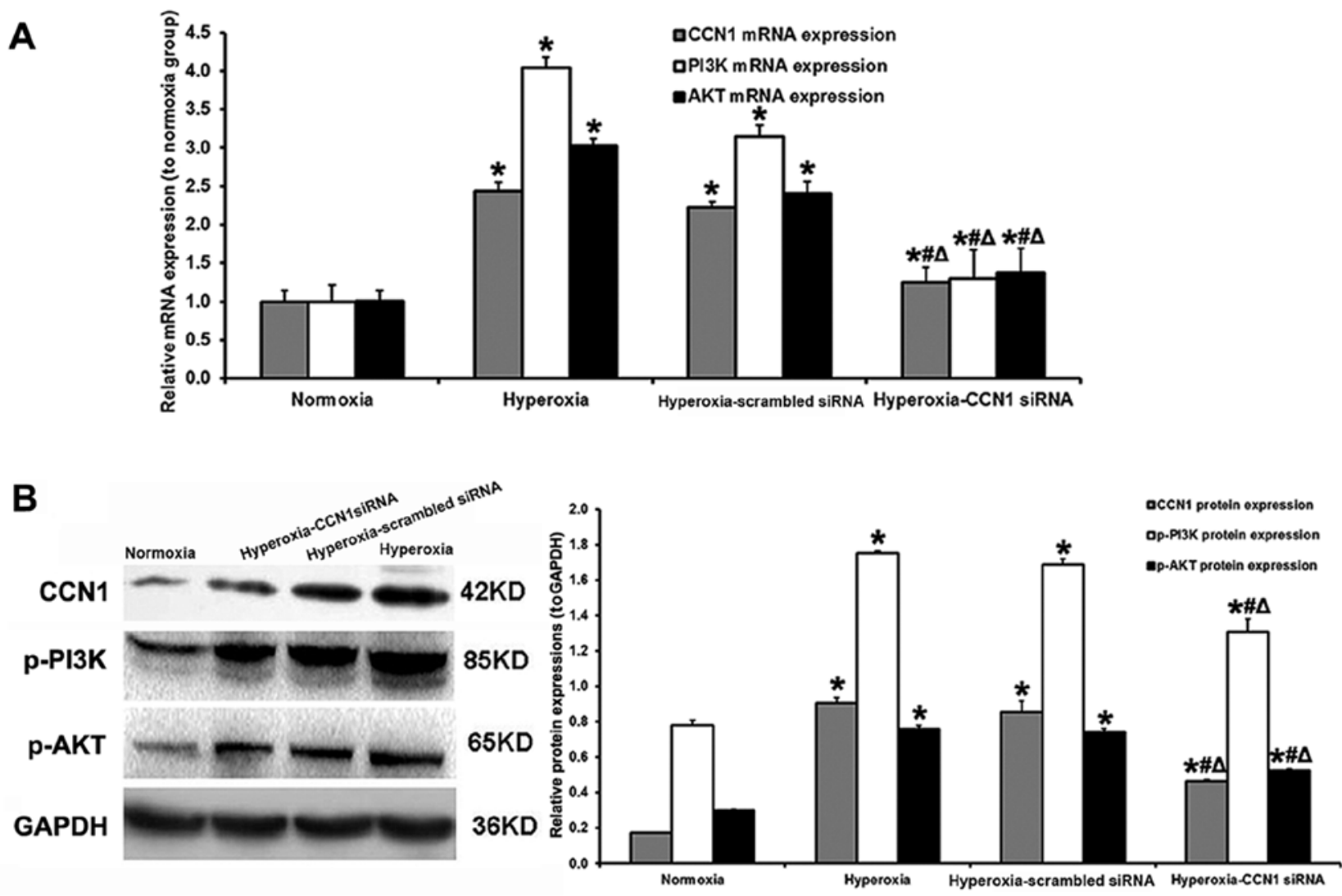

Figure 5. CCN family member 1 (CCN1) siRNA inhibits retinal neovascularization through the inhibition of the phosphoinositide 3-kinase (PI3K)/AKT signaling pathway in mouse pups with oxygen-induced retinopathy (OIR). (A) CCN1, PI3K and AKT mRNA expression levels were measured by RT-qPCR GAPDH) was used as an internal control. (B) CCN1, p-PI3K and p-AKT protein expression levels were measured by western blot analysis. Protein expression was normalized to GAPDH. Data are presented as the means $\pm \mathrm{SD}(\mathrm{n}=9)$. ${ }^{*} \mathrm{P}<0.05$ vs. the normoxia group; ${ }^{*} \mathrm{P}<0.05$ vs. the hyperoxia group; ${ }^{\triangle} \mathrm{P}<0.05$ vs. the hyperoxia-scrambled siRNA group.

$+122 \%$, respectively), PI3K (+404 and $+215 \%$, respectively) and AKT (+202 and $+140 \%$, respectively) expression levels were increased compared with the normoxia group (all $\mathrm{P}<0.05$; Fig. 5A). Compared with the hyperoxia-scrambled siRNA group, the administration of CCN1 siRNA decreased the CCN1, PI3K and AKT mRNA expression levels (-43.7, -58.7 and $-42.9 \%$, respectively, all $\mathrm{P}<0.05$; Fig. 5A).

Western blot analysis revealed similar results in the retinal samples. In the hyperoxia and hyperoxia-scrambled siRNA groups, the CCN1 (+429 and $+406 \%$, respectively), p-PI3K $(+124$ and $+115 \%$, respectively) and p-AKT $(+153$ and $+147 \%$, respectively) protein expression levels were increased compared with those in the normoxia group (all $\mathrm{P}<0.05$; Fig. 5B). Compared with the hyperoxia-scrambled siRNA group, the silencing of CCN1 by CCN1 siRNA decreased the CCN1, PI3K and AKT protein expression levels $(-45.3,-22.5$ and $-28.4 \%$, respectively, all $\mathrm{P}<0.05$; Fig. 5B).

Immunohistochemistry was also performed to investigate the localization and expression levels of CCN1, p-PI3K and p-AKT (Fig. 6). Immunohistochemistry of the retinal sections revealed that the $\mathrm{CCN} 1, \mathrm{p}-\mathrm{PI} 3 \mathrm{~K}$ and p-AKT expression levels were weakly detected only in the ganglion cell layer (GCL) and inner plexiform layer (IPL) of the normoxia group, whereas in the hyperoxia and hyperoxia-scrambled siRNA groups, they were strongly detected in the GCL, IPL, inner nuclear layer (INL) and outer plexiform layer (OPL), with neovascu- larization breaking through the ILM. However, the expression of CCN1, p-PI3K and p-AKT in the hyperoxia-CCN1 siRNA group was low in the GCL, IPL with less neovascularization breaking through the ILM compared with the hyperoxia and hyperoxia-scrambled siRNA groups.

\section{Discussion}

The aim of the present study was to assess the angiogenic effects of CCN1/Cyr61 in HUVECs, as well as the effects of CCN1/Cyr61-PI3K/AKT signaling in the retinas of mouse pups with OIR. CCN1 knockdown decreased CCN1, PI3K and AKT mRNA and protein expression, inhibited HUVEC proliferation and induced HUVEC apoptosis under hypoxic conditions. CCN1 knockdown resulted in less severe neovascularization in the eyes of the mouse pups with OIR. Exposure to hypoxia increased the number of preretinal neovascular cells, as well as CCN1, PI3K and AKT protein and mRNA expression. CCN1 silencing also decreased the number of hypoxic preretinal neovascular cells, as well as CCN1, PI3K and AKT mRNA and protein expression.

Previous studies have directly (38-41), as well as indirectly $(29,42)$ demonstrated that CCN1/CYR61 promotes chorioretinal angiogenesis in vitro via endothelial cell proliferation, migration and the formation of tubular structures, and that CYR61 plays a role in the formation of new blood vessels 

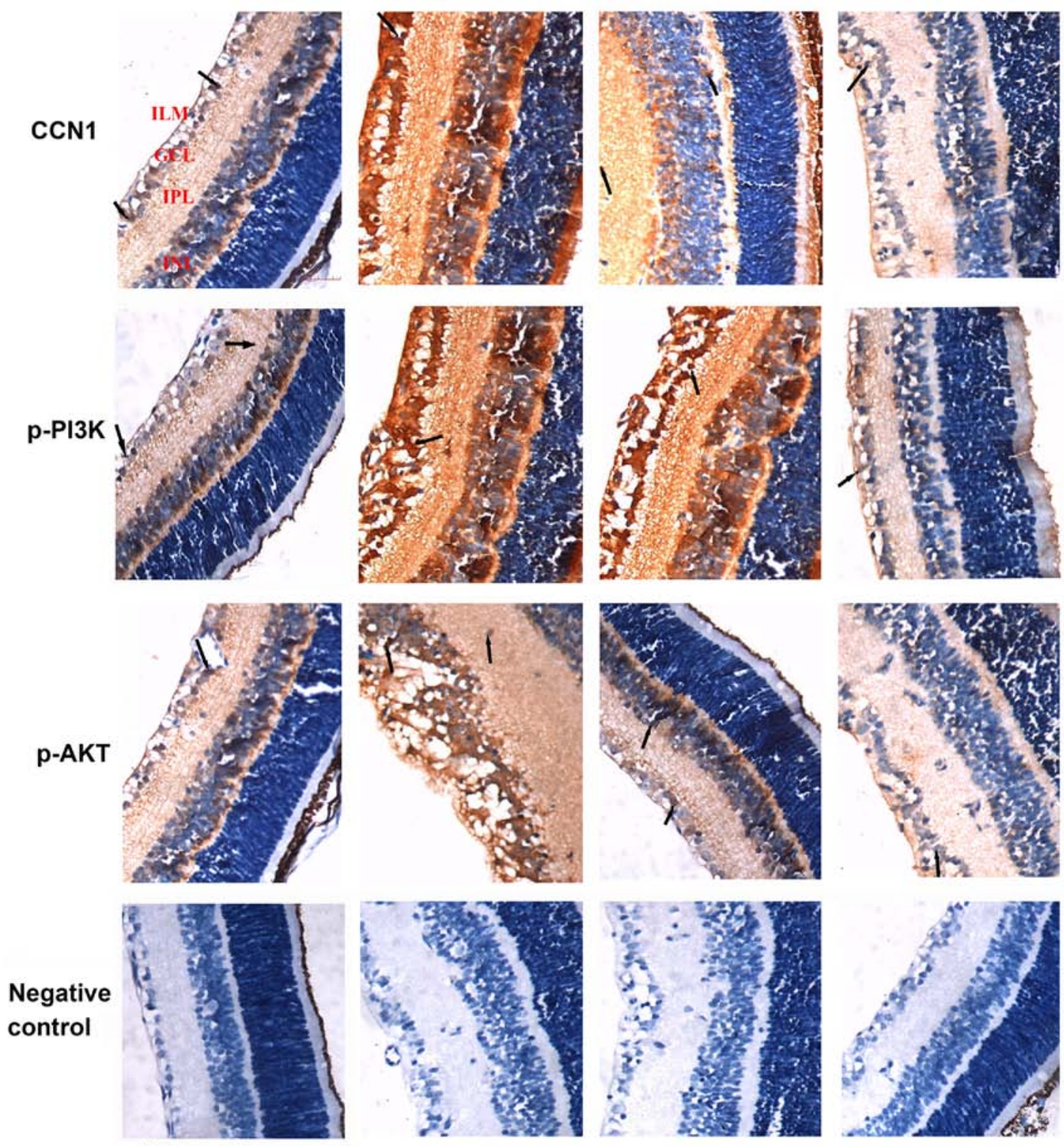

Hyperoxia

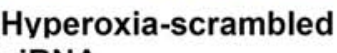

SIRNA

SIRNA

Figure 6. CCN family member 1 (CCN1) siRNA inhibits retinal neovascularization through the inhibition of the phosphoinositide 3-kinase (PI3K)/AKT signaling pathway in mouse pups with oxygen-induced retinopathy (OIR). CCN1, p-PI3K , and p-AKT protein expression were determined by immunohistochemistry (magnification, x400). Black arrows indicate CCN1-, p-PI3K- or p-AKT-positive cells. ILM, inner limiting membrane; GCL, ganglion cell layer; IPL, inner plexiform layer; INL, inner nuclear layer.

in the retina. All these processes begin with endothelial cell proliferation. The potent pro-angiogenic properties of CCN1 have previously been demonstrated in rat models of ischemic retinopathy $(29,31)$ and in relation to different tumor cell types $(37,43,44)$. As hyperoxia and subsequent angiogenesis play important roles in tumor development, a high $\mathrm{CCN} 1$ expression is associated with more aggressive tumor invasion. In experiments using HUVECs, CCN1 has been shown to induce endothelial cell proliferation (14-16,45). Accordingly, the present study demonstrated that the silencing of CCN1 using CCN1 siRNA significantly inhibited endothelial cell proliferation and promoted endothelial cell apoptosis, thus interfering with angiogenesis, as observed in the retinas of the mouse pups with OIR. However, these experiments were not designed to determine whether apoptosis prevented angiogen- esis, or whether apoptosis was induced as angiogenesis was inhibited. These results suggest that the CCN1/Cyr61 levels play a role in cell proliferation and apoptosis. This hypothesis is supported by the findings of previous studies which showed that endothelial cell proliferation is the first step in angiogenesis and must occur before cells can migrate and begin to form tubes $(18,42)$. However, a recent study suggested that CCN1 itself may be pro-apoptotic (46). This discrepancy may be due to a number of factors, including the animal model, cell lines, studied tissues or the methods used to determine apoptosis. Further studies are thus warranted in order to investigate these issues.

PI3K/AKT activation is both necessary and sufficient in itself to promote angiogenesis $(47,48)$. The inhibition of the PI3K/AKT pathway usually results in successful anti- 
angiogenic and anti-tumor effects (49). In addition, it has been previously reported that CCN1 induces PI3K/AKT expression in different types of cells, such as breast cancer cells, gastric cancer cells, renal cell carcinoma and glioma cells (37,50-52). In the present study, we examined angiogenesis-related signaling pathways to further elucidate the underlying mechanisms of the anti-angiogenic properties of silencing CCN1. We demonstrated that the silencing of CCN1 by CCN1 siRNA inhibited the activation of the PI3K/AKT pathway, which is consistent with the decreased angiogenesis observed in the mouse pups administered CCN1 siRNA. In addition, our results demonstrated that cells exposed to hypoxia and treated with LY294002, a PI3K inhibitor, had a lower early apoptotic rate but a higher late apoptotic rate compared with the cells exposed to hypoxia not treated with the inhibitor. In addition, the CCN1 mRNA and protein expression levels were markedly decreased following the silencing of CCN1. This suggested that angiogenesis was prevented by endothelial cell apoptosis and that PI3K is involved in the process.

We observed that exposure to hypoxia increased the mRNA and protein levels of CCN1 in vitro and in vivo via the phosphorylation of PI3K/AKT. In our mouse pup model of OIR, immunohistochemical analysis indicated that the expression levels of CCN1, p-PI3K and p-AKT in the neovascular tufts of the retinas and retinal angiogenesis were prevented by an intravitreal injection of CCN1 siRNA. The silencing of CCN1 by CCN1 siRNA effectively and specifically downregulated CCN1 expression in the retinas and HUVECs. CCN1 siRNA induced a significant inhibition of PI3K/AKT and also induced apoptosis. This study thus provides evidence that an increased CCN1 expression contributes to increased levels of PI3K/AKT and angiogenesis in retinas with OIR and HUVECs, and that CCN1 may be a target for the treatment of angiogenic retinopathy. Our findings are consistent with those of previously published studies, indicating that Cyr61 enhances gastric cancer invasion via PI3K/AKT $(37,51,52)$. The results of the present study support the hypothesis that the CCN1/Cyr61$\mathrm{PI} 3 \mathrm{~K} / \mathrm{AKT}$ signaling pathway plays an important role in the development of ROP.

However, we observed that endothelial cell proliferation, retinal angiogenesis and the expression levels of CCN1, PI3K and AKT were not completely inhibited by CCN1 siRNA. This phenomenon is likely related to a number of factors, including different plasmid vectors, transfection efficiencies $(53,54)$ and several other growth factors such as VEGF, basic fibroblast growth factor (bFGF), interleukin-8 (IL-8), c-Jun and HIF-1 $\alpha$ (55-59). Further studies are thus required to define the precise association of these growth factors with $\mathrm{CCN} 1$, and their involvement in retinopathies.

$\mathrm{CCN} 1$ expression is regulated by mitogenic factors such as VEGF, fibroblast growth factor (FGF) and platelet-derived growth factor (PDGF) (60). CCN1 is downregulated during tissue involution, in avascular tissues and in conditions associated with vascular obliteration, underlining the role of this protein in the vasculature (31). Forkhead box O3A (FOXO3a) inhibits smooth muscle cell proliferation via CCN1 inhibition (61). CCN1 activates the Ras pathway through the MAPK and AKT signaling pathways and enhances the expression of regulatory proteins that promote cell cycle progression $(62,63)$. However, there is a possibility of an auto- crine loop since VEGF is partly under CCN1 regulation (64). HIF plays a crucial role in the cell response to hypoxia. In tumor cells, VEGF is transactivated by HIF-1 $\alpha$ and plays a role in tumor progression and invasion (65). In gastric cancer, $\mathrm{CCN} 1$ promotes tumor progression via the HIF-1 $\alpha$-dependent upregulation of plasminogen activator inhibitor-1 (PAI-1) (52). In the present study, VEGF and HIF were not examined. Nevertheless, our results demonstrated that the silencing of CCN1 decreased cell proliferation, and that similar effects were achieved using a PI3K/AKT inhibitor, suggesting that AKT is involved. However, many aspects of CCN1 signaling remain unknown and thus further studies are warranted (66).

In conclusion, our results demonstrated that CCN1 plays an important role in HUVECs under hypoxic conditions and retinal apoptosis/angiogenesis in ROP via PI3K/AKT signaling. Thus, we suggest that $\mathrm{CCN} 1$ is a potential target for the prevention and treatment of ROP. This study also provides strong support for the view that siRNA therapy may play an important role in future therapeutic strategies.

\section{Acknowledgements}

We would like to thank Dr Jijing Pang, from the Department of Ophthalmology, University of Florida, for kindly providing the intravitreal injection needle. This study was supported by the National Natural Science Foundation of China (no. 81371045 to X.C.) and the Liaoning Province Technology Foundation of China (no. 2010225034 to X.C.).

\section{References}

1. Li Z, He T, Du K, Xing YQ, Yan Y, Chen Z, Zhang H and Shen Y: Overexpression of 15-lipoxygenase-1 in oxygen-induced ischemic retinopathy inhibits retinal neovascularization via downregulation of vascular endothelial growth factor-A expression. Mol Vis 18: 2847-2859, 2012.

2. Nowak-Sliwinska P, Storto M, Cataudella T, Ballini JP, Gatz R, Giorgio $\mathrm{M}$, van den Bergh $\mathrm{H}$, Plyte $\mathrm{S}$ and Wagnières G: Angiogenesis inhibition by the maleimide-based small molecule GNX-686. Microvasc Res 83: 105-110, 2012.

3. Gergely K and Gerinec A: Retinopathy of prematurity - epidemics, incidence, prevalence, blindness. Bratisl Lek Listy 111: 514-517, 2010.

4. Wang F, Bai Y, Yu W, Han N, Huang L, Zhao M, Zhou A, Zhao M and Li X: Anti-angiogenic effect of KH902 on retinal neovascularization. Graefes Arch Clin Exp Ophthalmol 251: 2131-2139, 2013.

5. Hartnett ME and Penn JS: Mechanisms and management of retinopathy of prematurity. N Engl J Med 367: 2515-2526, 2012.

6. Phelps DL: Retinopathy of prematurity. Pediatr Rev 16: 50-56, 1995.

7. No authors listed: Cryotherapy for Retinopathy of Prematurity Cooperative Group: Multicenter trial of cryotherapy for retinopathy of prematurity. 3 1/2-year outcome - structure and function. Arch Ophthalmol 111: 339-344, 1993.

8. Xia XB, Xiong SQ, Song WT, Luo J, Wang YK and Zhou RR: Inhibition of retinal neovascularization by siRNA targeting VEGF(165). Mol Vis 14: 1965-1973, 2008.

9. Yan Y, He T, Shen Y, Chen X, Diao B, Li Z, Liu Q and Xing YQ: Adenoviral 15-lipoxygenase-1 gene transfer inhibits hypoxiainduced proliferation of retinal microvascular endothelial cells in vitro. Int J Ophthalmol 5: 562-569, 2012.

10. Mintz-Hittner HA: Treatment of retinopathy of prematurity with vascular endothelial growth factor inhibitors. Early Hum Dev 88: 937-941, 2012.

11. Martínez-Castellanos MA, Schwartz S, Hernández-Rojas ML, Kon-Jara VA, García-Aguirre G, Guerrero-Naranjo JL, Chan RV and Quiroz-Mercado $\mathrm{H}$ : Long-term effect of antiangiogenic therapy for retinopathy of prematurity up to 5 years of follow-up. Retina 33: 329-338, 2013. 
12. Hanna M, Liu H, Amir J, Sun Y, Morris SW, Siddiqui MA, Lau LF and Chaqour B: Mechanical regulation of the proangiogenic factor CCN1/CYR61 gene requires the combined activities of MRTF-A and CREB-binding protein histone acetyltransferase. J Biol Chem 284: 23125-23136, 2009.

13. Jun JI and Lau LF: Taking aim at the extracellular matrix: CCN proteins as emerging therapeutic targets. Nat Rev Drug Discov 10: 945-963, 2011.

14. Brigstock DR: The connective tissue growth factor/cysteinerich 61/nephroblastoma overexpressed (CCN) family. Endocr Rev 20: 189-206, 1999.

15. Brigstock DR: The CCN family: a new stimulus package. J Endocrinol 178: 169-175, 2003.

16. Brigstock DR: Regulation of angiogenesis and endothelial cell function by connective tissue growth factor (CTGF) and cysteine-rich 61 (CYR61). Angiogenesis 5: 153-165, 2002.

17. Yan L and Chaqour B: Cysteine-rich protein 61 (CCN1) and connective tissue growth factor $(\mathrm{CCN} 2)$ at the crosshairs of ocular neovascular and fibrovascular disease therapy. J Cell Commun Signal 7: 253-263, 2013.

18. Choi J, Lin A, Shrier E, Lau LF, Grant MB and Chaqour B Degradome products of the matricellular protein CCN1 as modulators of pathological angiogenesis in the retina. J Bio Chem 288: 23075-23089, 2013

19. Chen CC and Lau LF: Functions and mechanisms of action of CCN matricellular proteins. Int J Biochem Cell Biol 41: 771-783, 2009.

20. Yang XM, Wang YS, Zhang J, Li Y, Xu JF, Zhu J, Zhao W, Chu DK and Wiedemann P: Role of PI3K/Akt and MEK/ERK in mediating hypoxia-induced expression of HIF-1alpha and VEGF in laser-induced rat choroidal neovascularization. Invest Ophthalmol Vis Sci 50: 1873-1879, 2009.

21. You JJ, Yang CH, Yang CM and Chen MS: Cyr61 induces the expression of monocyte chemoattractant protein-1 via the integrin $\alpha v \beta 3$, FAK, PI3K/Akt, and NF- $\kappa \mathrm{B}$ pathways in retinal vascular endothelial cells. Cell Signal 26: 133-140, 2014.

22. Sasore T, Reynolds AL and Kennedy BN: Targeting the $\mathrm{PI} 3 \mathrm{~K} / \mathrm{Akt} / \mathrm{mTOR}$ pathway in ocular neovascularization. Adv Exp Med Biol 801: 805-811, 2014

23. Guo H, Lv Y, Tian T, Hu TH, Wang WJ, Sui X, Jiang L, Ruan ZP and Nan KJ: Downregulation of p57 accelerates the growth and invasion of hepatocellular carcinoma. Carcinogenesis 32 : 1897-1904, 2011

24. Han Z, Yang Q, Liu B, Wu J, Li Y, Yang C and Jiang Y: MicroRNA-622 functions as a tumor suppressor by targeting $\mathrm{K}$-Ras and enhancing the anticarcinogenic effect of resveratrol. Carcinogenesis 33: 131-139, 2012.

25. Aubry JP, Blaecke A, Lecoanet-Henchoz S, Jeannin P, Herbault N, Caron G, Moine V and Bonnefoy JY: Annexin V used for measuring apoptosis in the early events of cellular cytotoxicity. Cytometry 37: 197-204, 1999.

26. Vermes I, Haanen C, Steffens-Nakken $H$ and Reutelingsperger $C$ : A novel assay for apoptosis. Flow cytometric detection of phosphatidylserine expression on early apoptotic cells using fluorescein labelled Annexin V. J Immunol Methods 184: 39-51, 1995.

27. Smith LE, Wesolowski E, McLellan A, Kostyk SK, D'Amato R, Sullivan R and D'Amore PA: Oxygen-induced retinopathy in the mouse. Invest Ophthalmol Vis Sci 35: 101-111, 1994.

28. Masuda I, Matsuo T, Yasuda T and Matsuo N: Gene transfer with liposomes to the intraocular tissues by different routes of administration. Invest Ophthalmol Vis Sci 37: 1914-1920, 1996.

29. You JJ, Yang CH, Chen MS and Yang CM: Cysteine-rich 61, a member of the CCN family, as a factor involved in the pathogenesis of proliferative diabetic retinopathy. Invest Ophthalmol Vis Sci 50: 3447-3455, 2009.

30. Zhang Q, Zhang J, Guan Y, Zhang S, Zhu C, Xu GT and Wang L: Suppression of retinal neovascularization by the iNOS inhibitor aminoguanidine in mice of oxygen-induced retinopathy. Graefes Arch Clin Exp Ophthalmol 247: 919-927, 2009.

31. Hasan A, Pokeza N, Shaw L, Lee HS, Lazzaro D, Chintala H, Rosenbaum D, Grant MB and Chaqour B: The matricellular protein cysteine-rich protein 61 (CCN1/Cyr61) enhances physiological adaptation of retinal vessels and reduces pathological neovascularization associated with ischemic retinopathy. J Biol Chem 286: 9542-9554, 2011.

32. Lambert V, Lecomte J, Hansen S, Blacher S, Gonzalez ML, Struman I, Sounni NE, Rozet E, de Tullio P, Foidart JM, et al: Laser-induced choroidal neovascularization model to study agerelated macular degeneration in mice. Nat Protoc 8: 2197-2211, 2013.
33. Ecoiffier T, Yuen D and Chen L: Differential distribution of blood and lymphatic vessels in the murine cornea. Invest Ophthalmol Vis Sci 51: 2436-2440, 2010.

34. Barnett JM, McCollum GW, Fowler JA, Duan JJ, Kay JD, Liu RQ, Bingaman DP and Penn JS: Pharmacologic and genetic manipulation of MMP-2 and -9 affects retinal neovascularization in rodent models of OIR. Invest Ophthalmol Vis Sci 48: 907-915, 2007.

35. Park K, Chen Y, Hu Y, Mayo AS, Kompella UB, Longeras R and Ma JX: Nanoparticle-mediated expression of an angiogenic inhibitor ameliorates ischemia-induced retinal neovascularization and diabetes-induced retinal vascular leakage. Diabetes 58: 1902-1913, 2009.

36. Livak KJ and Schmittgen TD: Analysis of relative gene expression data using real-time quantitative PCR and the 2(-Delta Delta C(T)) Method. Methods 25: 402-408, 2001.

37. Smith LE: Pathogenesis of retinopathy of prematurity. Acta Paediatr Suppl 91: 26-28, 2002.

38. Grote K, Salguero G, Ballmaier M, Dangers M, Drexler H and Schieffer B: The angiogenic factor CCN1 promotes adhesion and migration of circulating CD34+ progenitor cells: potential role in angiogenesis and endothelial regeneration. Blood 110: 877-885, 2007.

39. Leu SJ, Lam SC and Lau LF: Pro-angiogenic activities of CYR61 (CCN1) mediated through integrins alphavbeta3 and alpha6beta1 in human umbilical vein endothelial cells. J Biol Chem 277 46248-46255, 2002.

40. Kireeva ML, Latinkić BV, Kolesnikova TV, Chen CC, Yang GP, Abler AS and Lau LF: Cyr61 and Fisp12 are both ECM-associated signaling molecules: Activities, metabolism, and localization during development. Exp Cell Res 233: 63-77, 1997.

41. Kireeva ML, Mo FE, Yang GP and Lau LF: Cyr61, a product of a growth factor-inducible immediate-early gene, promotes cell proliferation, migration, and adhesion. Mol Cell Biol 16: 1326-1334, 1996

42. Zhang X, Yu W and Dong F: Cysteine-rich 61 (CYR61) is up-regulated in proliferative diabetic retinopathy. Graefes Arch Clin Exp Ophthalmol 250: 661-668, 2012.

43. Meyuhas R, Pikarsky E, Tavor E, Klar A, Abramovitch R, Hochman J, Lago TG and Honigman A: A Key role for cyclic AMP-responsive element binding protein in hypoxia-mediated activation of the angiogenesis factor CCN1 (CYR61) in Tumor cells. Mol Cancer Res 6: 1397-1409, 2008.

44. Leask A: CCN1: A novel target for pancreatic cancer. J Cell Commun Signal 5: 123-124, 2011.

45. Perbal B: CCN proteins: multifunctional signalling regulators. Lancet 363: 62-64, 2004.

46. Su BC and Mo FE: CCN1 enables Fas ligand-induced apoptosis in cardiomyoblast $\mathrm{H} 9 \mathrm{c} 2$ cells by disrupting caspase inhibitor XIAP. Cell Signal 26: 1326-1334, 2014.

47. Gerszten RE, Friedrich EB, Matsui T, Hung RR, Li L, Force T and Rosenzweig A: Role of phosphoinositide 3-kinase in monocyte recruitment under flow conditions. J Biol Chem 276: 26846-26851, 2001.

48. Zheng ZZ and Liu ZX: Activation of the phosphatidylinositol 3-kinase/protein kinase Akt pathway mediates CD151-induced endothelial cell proliferation and cell migration. Int J Biochem Cell Biol 39: 340-348, 2007.

49. Quan Y, Wang N, Chen Q, Xu J, Cheng W, Di M, Xia W and Gao WQ: SIRT3 inhibits prostate cancer by destabilizing oncoprotein $\mathrm{C}-\mathrm{MYC}$ through regulation of the PI3K/Aktpathway. Oncotarget 6: 26494-26507, 2015.

50. Long QZ, Zhou M, Liu XG, Du YF, Fan JH, Li X and He DL: Interaction of CCN1 with $\alpha v \beta 3$ integrin induces P-glycoprotein and confers vinblastine resistance in renal cell carcinoma cells. Anticancer Drugs 24: 810-817, 2013.

51. Lin BR, Chang CC, Chen LR, Wu MH, Wang MY, Kuo IH, Chu CY, Chang KJ, Lee PH, Chen WJ, et al: Cysteine-rich 61 (CCN1) enhances chemotactic migration, transendothelial cell migration, and intravasation by concomitantly up-regulating chemokine receptor 1 and 2. Mol Cancer Res 5: 1111-1123, 2007.

52. Lin MT, Kuo IH, Chang CC, Chu CY, Chen HY, Lin BR, Sureshbabu M, Shih HJ and Kuo ML: Involvement of hypoxiainducing factor-1alpha-dependent plasminogen activator inhibitor-1 up-regulation in Cyr61/CCN1-induced gastric cancer cell invasion. J Biol Chem 283: 15807-15815, 2008.

53. Hanrahan F, Humphries P and Campbell M: RNAi-mediated barrier modulation: synergies of the brain and eye. Ther Deliv 1: 587-594, 2010. 
54. Roy S, Nasser S, Yee M, Graves DT and Roy S: A long-term siRNA strategy regulates fibronectin overexpression and improves vascular lesions in retinas of diabetic rats. Mol Vis 17: 3166-3174, 2011.

55. Kuwabara K, Ogawa S, Matsumoto M, Koga S, Clauss M, Pinsky DJ, Lyn P, Leavy J, Witte L and Joseph-Silverstein J: Hypoxia-mediated induction of acidic/basic fibroblast growth factor and platelet-derived growth factor in mononuclear phagocytes stimulates growth of hypoxic endothelial cells. Proc Natl Acad Sci USA 92: 4606-4610, 1995.

56. Kunz M, Hartmann A, Flory E, Toksoy A, Koczan D, Thiesen HJ, Mukaida N, Neumann M, Rapp UR, Bröcker EB and Gillitzer R: Anoxia-induced up-regulation of interleukin-8 in human malignant melanoma. A potential mechanism for high tumor aggressiveness. Am J Pathol 155: 753-763, 1999.

57. Yamashita K, Discher DJ, Hu J, Bishopric NH and Webster KA: Molecular regulation of the endothelin-1 gene by hypoxia. Contributions of hypoxia-inducible factor-1, activator protein-1, GATA-2, AND p300/CBP. J Biol Chem 276: 12645-12653, 2001.

58. Woo KJ, Lee TJ, Park JW and Kwon TK: Desferrioxamine, an iron chelator, enhances HIF-1alpha accumulation via cyclooxygenase-2 signaling pathway. Biochem Biophys Res Commun 343: 8-14, 2006.

59. You JJ, Yang CM, Chen MS and Yang CH: Regulation of Cyr61/CCN1 expression by hypoxia through cooperation of c-Jun/AP-1 and HIF-1 $\alpha$ in retinal vascular endothelial cells. Exp Eye Res 91: 825-836, 2010.
60. Chaqour B and Goppelt-Struebe M: Mechanical regulation of the Cyr61/CCN1 and CTGF/CCN2 proteins. FEBS J 273: 3639-3649, 2006.

61. Lee HY, Chung JW, Youn SW, Kim JY, Park KW, Koo BK, Oh BH, Park YB, Chaqour B, Walsh K and Kim HS: Forkhead transcription factor FOXO3a is a negative regulator of angiogenic immediate early gene CYR61, leading to inhibition of vascular smooth muscle cell proliferation and neointimal hyperplasia. Circ Res 100: 372-380, 2007.

62. Chen CC, Chen N and Lau LF: The angiogenic factors Cyr61 and connective tissue growth factor induce adhesive signaling in primary human skin fibroblasts. J Biol Chem 276: 10443-10452, 2001.

63. Murphy LO, MacKeigan JP and Blenis J: A network of immediate early gene products propagates subtle differences in mitogenactivated protein kinase signal amplitude and duration. Mol Cell Biol 24: 144-153, 2004.

64. Mo FE, Muntean AG, Chen CC, Stolz DB, Watkins SC and Lau LF: CYR61 (CCN1) is essential for placental development and vascular integrity. Mol Cell Biol 22: 8709-8720, 2002.

65. Zhong H, De Marzo AM, Laughner E, Lim M, Hilton DA, Zagzag D, Buechler P, Isaacs WB, Semenza GL and Simons JW: Overexpression of hypoxia-inducible factor 1alpha in common human cancers and their metastases. Cancer Res 59: 5830-5835, 1999.

66. Chaqour B: Molecular control of vascular development by the matricellular proteins CCN1 (Cyr61) and CCN2 (CTGF). Trends Dev Biol 7: 59-72, 2013 